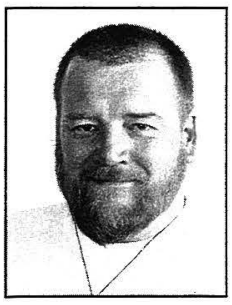

\title{
RELEASING THE Potential OF NURSING LABOUR
}

\author{
Michael Pye \\ The University of Waikato
}

\begin{abstract}
The recent release of the "Report of the Ministerial Taskforce on Nursing: Releasing the Potential of Nursing" provides a useful point of reference to analyse again the changing division of labour in the production of health and sickness services in New Zealand following a period of significant reform. Sociological inquiry into the relationships between the various occupational groups engaged in the provision of health services has, in the past, tended to focus on the professionalising projects of the respective occupations, and on the contestation/cooperation at the 'closure boundaries' between those groups. This paper argues that, in the reformed health sector, with its cascade of principals and agents, output based contracts and contestable contracting, the historic form of analysis is adequate. A different form of analysis is needed to explore the new changing relationships both within and between the health occupational groups themselves; and secondly and perhaps more importantly, to analyse the changing relationships between the health industry occupations and the State.
\end{abstract}

Keywords: nursing, labour process, division of labour

The recent release of the "Report of the Ministerial Taskforce on Nursing: Releasing the potential of nursing" provides a useful point of reference to begin to analyse again the changing division of labour in the production of health and sickness services in New Zealand - particularly as this report has been produced following a period of significant reform. Sociological inquiry into the relationships between the various occupational groups engaged in the provision of health services has, in the past, tended to focus on the professionalising projects of the respective occupations and on the contestation/co-operation at the 'closure boundaries' between those groups. This type of analysis was appropriate at a time when the occupational groups in the health sector had a significant degree of 'autonomy' in determining the outcomes of their labour and the division of that labour.

This paper argues that, in the reformed health sector, with its cascade of principals and agents, output based contracts and contestable contracting, the historic form of analysis alone is inadequate. A different form of analysis is needed to explore the new and changing relationships both within and between the health occupational groups themselves. Secondly, and perhaps more importantly, it.is needed to analyse the changing relationships between the health industry occupations and the State (and its agents) as the prime principal, major funder, employer and regulator of workers in the health and sickness industry. Using the Nursing Taskforce as a focus, this paper analyses the developments to date and speculates on the future as the state seeks to reregulate the labour of the health occupations.
This paper examines what potentially might be a significant development in the regulation of the division of labour and of the labour process in the production of health and sickness services in New Zealand. That development is the direct intervention by the State, as it combines several of its roles in the health and sickness sector. These roles include its role as legislator and regulator, and secondly the Government's role as the primary funder of health and sickness services. Thirdly it includes the Government's role as a significant owner of health and sickness service providers in the form of Hospital and Health Services. Public and private hospitals together are New Zealand's largest industry and the dominant means of delivering health and sickness services, and accounted for approximately $\$ 4.03$ billion dollars of public and private spending in 1996/ 97 (Devlin \& O'Dea, 1998). A significant majority of that was spent in state owned hospitals and related services. Finally it is in the Government's role as the prime principal in a chain of principals and agents, contracting and subcontracting one with another over the funding and provision of health and sickness services, that makes this postulated new form of intervention and regulation most interesting.

The health reforms that were initiated in 1991 were intended to introduce two key elements into the health and sickness industry; competition in both the funding and provision of health and sickness services and secondly the application of agency theory to the organisation of those services. The competition element was to be introduced by the separating the funders and providers and by having the providers 
competitively tender with the funders to provide predetermined contractual outcomes for a set price (Ashton, 1999; Burnett \& Malcolm, 1997; Easton, 1997; Imershein \& Estes, 1996; Upton, 1991). The application of agency theory was to be implemented by having each player in the industry relating to each other at arm's length through the mechanism of contracts between a principal (usually a funder) and an agent (usually a provider) acting on behalf of the principal in undertaking to provide clearly defined outcomes with clear accountability for those outcomes. That the outcome of the health reforms have not equalled the intentions is undisputed by all but a very few, the relative success or otherwise is a matter of debate and the issues have been canvassed widely (see for instance Ashton, 1999; Devlin \& O'Dea, 1998; Easton, 1997; Fougere, 1994; Fougere, 1997). It is not intended in this paper to canvass all of these matters again but to concentrate on two related aspects that have affected the progress and outcomes of the health reforms: the division of labour and the control of the labour process in the production of health and sickness services as they relate to agency and contract.

Health workers can be generally divided into five broad groups:

- The licensed 'health professionals', that group of occupations whose members are subject to state regulation. These groups of workers are usually directly involved in various research, diagnostic, therapeutic and health maintenance tasks.

- Associated with this first group are a diverse number of auxiliary workers who assist the health professionals in some of the primary groups' activities and who are sometimes involved in contestations with their superiors over both the horizontal and lateral divisions of labour within the occupational groups' traditional orbit (Pye, 1998).

- The other three groups are the managerial and administrative workers, either generic or health industry specific, the hotel domestic, catering and support services workers, and what might be broadly defined as trades, technical and scientific workers.

The particular contribution that each of these groups make to the workforce in any particular health and sickness service production facility is dependent on a number of factors. For instance:

- the ownership of the facility, either state or private

- its legal form, partnership, company or trust

- whether it is, or is not, for profit

- the particular managerial form adopted: management by clinicians, generic general management, or new public sector managerialism

- clearly the size of the organisation, the type and complexity of the production tasks being undertaken including whether or not it is a teaching as well as clinical institution (For a useful discussion of many of these factors see Heydebrand, 1973)
- the size of the institutions' staffing budget relative to the factors mentioned above has a major impact on the rigidity of the demarcations between different occupational groups

A particularly interesting factor given the twenty four hour a day seven day a week nature of much of the industry, especially hospitals, is how the time of the day and the day of the week affects the rigidity of the task boundaries. During the late afternoon and night and at the weekends there is one occupational group - nurses, whose boundaries stretch quite markedly to cover the tasks of those groups of workers who tend to have more traditional hours of work (Pye, 1998). (The author, in a previous incarnation as a nurse who has been on far too many night duties, clearly recollects having to undertake tasks that were normally the responsibility of; electricians, doctors, plumbers, physiotherapists, fitters, chaplains, orderlies, morticians, cooks, psychologists, carpenters, lab technicians, painters, occupational therapists and accountants. This is not an exhaustive list and could no doubt be added to by any nurse who has done their share of night duty in any reasonably sized hospital.)

While the organisational factors affecting the division of labour are of importance in the analysis of local variations and to an understanding of the conflicts and compromises around the occupational boundaries that occur at the immediate point of production, they have to be seen in the context of a wider and much deeper division of labour that exists particularly between the occupational groups and subgroups of the health professions.

The licensed 'health professions' are the core occupational groups of the health and sickness industry. It is their regulated, monopolistic/oligopolistic position of having control over the actual production of the industry's primary outputs, the myriad diagnostic and therapeutic activities that are currently available to achieve some change in the psycho-social and physiological state of an individual or group, that makes them core. It is the issues around the division of labour and of the control of the labour process of these groups that are primary determinants of efficiency and effectiveness in the health and sickness industry. As a consequence, governments, policy makers and managers of the health and sickness industry have always had an interest in how the division of labour amongst these groups has occurred and how the health and sickness labour process has been organised. In a survey of health sector human resource managers and industrial relations practitioners reported at an earlier LEW conference (Pye \& Cullinane, 1997) a number of the respondents identified the division of labour between the 'health professionals' as one of the key management issues in the post reform period. The current Minister of Health has also made comments which indicate a more than passing interest in changing the current division of labour ( NZ Government, 1997a; NZ Government, 1997b). The key difference in that interest and any outcomes that could arise from such interest in the preand post-reform era is: who were then, and who are now, the key managers and policy makers? 
For most of the period up until the late 1980 's, at almost all levels of the institutions involved in the health and sickness industry from the Department of Health down to the smallest public health clinic, the managers and policy makers were members of the 'health professions'; invariably doctors and nurses. These doctors and nurses were two arms of a triumvirate management structure with a senior nonmedical public servant, board secretary or hospital manager as the third part of that structure. The spheres of influence and areas of managerial control of each were jealously guarded; in particular the clinical divisions of labour were the sole domain of the health professionals. At both the institutional and central policy making levels, decisions about the division of health and sickness service labour were made directly by those who were intimately and professionally involved in and affected by the outcomes of those decisions. This power and influence over the division of labour was matched, to large degree, with the power the 'health professions' had in determining what would be the outputs and outcomes of the health and sickness service production process. These influences were reinforced by the lack of direct contractual accountability back to the funders, primarily the state. Those who paid the piper did not necessarily call the tune. The managerial and policy making power of the health professional elites was further enhanced by the public prestige and high standing with which the 'medical professions' were held by the public.

As a result the contestations over which occupational group would undertake which tasks in the complex division of health and sickness labour tended to occur within and between the various occupations with (for the most part) the public and politicians becoming aware of the outcomes after the fact. Very few of the contestations occurred in the public arena and then only when one or other side in the contest sought to gain public sympathy and support for their particular position. Two of the more notable of these were the dispute over midwifery in the early part of the century (Papps \& Olssen, 1997; Parkes, 1991) or the struggle between doctors and the first Labour Government (both of which the doctors won) (Lovell-Smith, 1966). A second and more important consequence of the health professions holding key managerial and policy positions was that the degree and scope of statutory regulation that impacted on the health and sickness service division of labour was very much influenced by the health professions and to large degree reflected the outcomes of the contestation between and within themselves. The statutory regulation covered a number of areas, the three most important of those being covered by the Acts of Parliament relating to: the registration and licensing of health workers; the provision of state subsidies and funding; and Acts that restricted certain activities to particular occupational groups.

The Acts that provided for registration or licensing of the various occupational groups were generally concerned with matters such as establishing the criteria for the educational qualifications necessary to gain entry into the profession and having gained entry, the subsequent behaviour of the practitioner. They frequently included provision for the exclusive use of certain titles by members of the occupational groups, reinforcing their position of difference. Where there were different classes or levels of practitioners within an occupation the Acts clearly established the hierarchical position, duties and responsibilities of each class relative to each other and, in some cases, relative to other completely separate occupational groups eg. Enrolled Nurses to Medical Practitioners. While these Acts rarely made specific reference, in a deterministic sense, to a particular set of tasks or activities that the relevant occupational group might do or might not do, they did establish boards or councils whose membership to a large extent reflected the managerial and policy elites discussed above. A consequence of this was that the administration of those Acts by these statutory boards and councils reflected and reinforced the division of labour that had been established in earlier contestations and that existed at the point of production.

Of greater significance to the determination and maintenance of the health and sickness services division of labour are those Acts and Regulations that specifically limit certain activities to a particular occupational group or fraction of that group. Some examples are legislation such as the Medicines Act and the Controlled Drugs Regulations which expressly limit the prescribing of a very long list of therapeutic substances to particular occupational groups and, in some cases, to particular classes within those occupational groups. Legislated monopoly access to the prescription and use of these therapeutic substances creates a very strong occupational boundary for the groups that have that monopoly against other groups in the industry. Of equal significance are those legislative and regulatory provisions about which practitioners, in any particular occupational group, can initiate access to state subsidy and/or referral to state subsidised practitioners or institutions. Examples are the Social Security and Accident Compensation legislation which gave almost complete monopoly access to a range of subsidies for primary medical care, laboratory and radiological tests, and to medications. Monopoly referral rights to subsidised therapeutic procedures such as physiotherapy, chiropody etc. or onto secondary public hospital care, provided another near absolute boundary in the division of health and sickness service labour. In the post reform era, it is in these latter two areas that government is exerting its power and influence as legislator to re-regulate the health and sickness service division of labour to meet its goals as the prime principal/agent and funder in the health and sickness service industry.

The first major change that affected the control of the division of labour and labour process in the production of health and sickness services during the health reforms was the restructuring of the industry's management structures and processes particularly in the public hospital sector. These changes started with amendments to both the Area Health Boards Act and State Sector Act in 1988. These amendments set aside a tradition of hospital and related organisational administration in which the health professions dominated the management of the health industry (as discussed above). These acts introduced concepts of generic general management with the appointing of managers who were not necessarily health professionals. The amendments also 
provided for the Chief Executive Officer of an Area Health Board to become the employer of all staff employed by the boards, removing the previous multiple sets of accountabilities and channels of communication that had allowed the various health professions to exert influence at different levels depending on the circumstances. The second major change was the dismissal of the Area Health Boards by Simon Upton which removed the health professionals and their sympathisers who were members of those boards from positions where they could directly influence staffing policy at the point of production. The new managers and the Commissioners which replaced the boards were operating under a new (for the health industry) set of imperatives with respect to the utilisation of the human resources they employed, in particular the health professionals (Pye \& Cullinane, 1997). Similar changes occurred in the Department of Health as health professionals employed within the department in senior managerial and policy positions lost power and influence during the restructuring of the department and the introduction of general management. Despite the possibilities for changing the health and sickness division of labour presented by these legislative changes, until recently, only one major change of national importance occurred.

This was the change to the status of midwives, who were given the opportunity to become independent practitioners with limited rights to prescribe, access to subsidies, rights of referral to public hospitals and access to laboratory tests etc. This in effect put them on a par with general practitioners in the maternity and childbirth segment of the health and sickness industry. While this change did not occur as a result of government initiated process, it was facilitated by the changes that were occurring during the reform period. The events that led to the changes for midwives were an example of the inter-professional contestation discussed above. It was a reversal of the process that had occurred in the early part of the century (discussed above), in which the midwives, in co-operation with well organised lobby groups in society and with the assistance of a sympathetic Minister of Health, convinced the government of the day to change the legislation. One of the consequences for the Government was that it was able to introduce competition into this segment of the health and sickness industry as a result of the increased number of potential agents with whom it could contract for the provision of maternity services. (One of the unintended consequences was that large numbers of general practitioners have exited this segment of the market for 'economic reasons' and given there are only slightly in excess of 250 midwives in any form of independent practice, choice and competition has, in fact, diminished in many parts of New Zealand) (Health, 1998). The relative success of this re-regulation of the division of labour has provided an example of how the Government might also re-regulate the division of labour in other sectors of the health and sickness market. In a marketised system of health and sickness care production, which is organised through a cascade of agents and principals, it is to the advantage of the Government, as the prime principal, and to its principal agents (the Health Funding Authority and the $\mathrm{ACC}$ ) to have the maximum number of potential agents available to contract with. It is equally advantageous to other agents, the healthcare providers, many of whom are also owned by the State, for them to have a large number of agents and sub-agents (including employees) with whom they can contract and sub-contract with for specific sets of outputs.

One of the factors that has contributed to the success and/ or failure of the health reforms has been the limitations on the number of available agents in particular areas with whom the State and its agents could contract. A significant limitation has been the fact that a number of the key productive activities can only be undertaken by members of the occupational groups which have legislative monopoly powers over the performance of those tasks. This has restricted the ability of policy makers and managers to maximise the utilisation of the human resources available in the production of the contracted outcomes. There are a number of ways in which this can be addressed. One is to increase the absolute number of people in the occupations who hold the monopoly power. This course is expensive, time consuming and has a long lead-time before it can have significant effect. A second course of action is to reduce the monopoly power by giving other workers in the sector access to those particular tasks. The Taskforce on Nursing appears to give a clear indication that the Government intends to proceed down the second of these courses using a consultative process rather than by executive fiat (at least in this instance).

The last set of published comprehensive data relating to 1994 (Health, 1996) indicated there were 61570 persons licensed as members of one of the thirteen regulated occupational groups in the health and sickness sector. Of these $46539(75 \%)$ were nurses of all levels. There were 7180 $(11.7 \%)$ doctors of all levels. Of all of the occupational groups, only two (nursing and medicine) can be said to have a generalist orientation, at least during the initial training and period of practice. All of the other groups tend to have a very specific focus on a set of pathologies, particular organ systems and specific therapeutic modalities. Where nursing has specialised its area of practice, these specialisms have tended to reflect and generally complement the specialisms of medicine - for example care of the aged and intensive care. Nursing, therefore, provides an excellent source of alternative workers (particularly to doctors) in a number of important areas of the health and sickness industry, but only if the regulatory frameworks and other barriers which prevent nurses from undertaking a number of tasks currently restricted to doctors are removed or modified. The clear intention of the Nursing Taskforce was to identify these barriers and suggest ways they could be removed.

It is beyond the brief of this paper to discuss the process and recommendation of the Taskforce. What is of particular importance is that the Taskforce was initiated by the Minister of Health; it was funded and materially supported by the Ministry with the clear intention of providing the Minister of Health with recommendations about the re-regulation of the division of labour in the health and sickness 
industry. No other occupational groups were represented on the Taskforce, though they were consulted. The Taskforce was initially chaired by an ex-member of Parliament who left to take up a diplomatic position, and who was subsequently replaced as chair by the only other nonnurse member, a health economist. There was one member whose tribal affiliation is mentioned and there were no males. All of the participants had position titles that indicated that they were in senior managerial, clinical, educational and/or policy positions. The Taskforce met without public or academic scrutiny and submissions were only sought by invitation (the invitations were widely distributed amongst nurses who were members of the Nurses Organisation through its journal). Broadly, the findings indicated that with some change to regulations, selected and appropriately trained nurses would be able to undertake a number of the tasks currently undertaken by doctors in a limited number of discrete areas of practice. The members of the Taskforce generally supported the proposed changes although there were some dissenting voices relating to the composition of the Nursing Council and to employment related matters. Naturally there was not such a positive response from doctors to the findings of the Taskforce. The Taskforce has subsequently been disbanded and features of its report are being investigated and actioned by the Ministry of Health.

\section{Conclusion}

The key conclusion that might be drawn from the Nursing Taskforce experience is that the Government sees itself, at least at this point in time, as having a central role in deciding the boundaries in the health and sickness division of labour, and the organisation of the associated labour process. The Government is taking upon itself a role that was previously left almost entirely to the health professions themselves. The Government is able to do this, firstly because it is, at the same time, the regulator, in many cases the employer, the principal funder and the primary princi$\mathrm{pal}$ in the health and sickness care industry. Secondly given the relative loss of influence and power of the health professions at the managerial and policy making levels in the industry, the Government is now able to exercise its power as a regulator to shape the agenda about the health and sickness division of labour for its own purposes.

\section{Future research}

Some of the questions that arise for researchers are:

- What impact will the changes in the regulation of the division of labour actually have on the composition and distribution of the health and sickness industry workforce? (There are already legislative changes being made with respect to the prescription of medicines)

- Was the Nursing Taskforce and its consequences a one off opportunistic event, or does it signal an intention by the Government to further actively intervene in the health and sickness division of labour (given that occupational regulation has been on the Government's agenda for some time)?
- What impact will these changes have on the relationships between the occupational groups at all levels, at the point of production and at the elite levels? One of the nursing elites, the Nurses Organisation, has already responded with a document 'Building Partnerships: Developing the Future of Nursing' (NZNO, 1998) which makes some clear assertions about boundaries and relationships.

- What are the potential impacts on employment and industrial relations in the health and sickness industry?

- How will the analysis and understanding of these changes in the processes of occupational regulation articulate with other modes of analysis eg. gender and class, that are applied to an understanding of health and sickness workers?

Given the centrality of the organisation and control of the division of Iabour to success or failure in the health and sickness industry, these and related questions require greater attention than they currently receive.

\section{References}

Ashton, T. (1999) The Health Reforms: To Market and Back? In T. Ashton, P. Dalziel, \& J. Boston (eds), Redesigning the New Zealand Welfare State. Auckland: Oxford University Press.

Burnett, P. \& Malcolm, L. (1997) Beyond Ideology: the emerging roles of New Zealand's Crown Health enterprises, International Journal of Health Services, 27(1), 89-108.

Devlin, N. \& O'Dea, D. (1998) Hospitals. In A. Bollard \& M. Pickford (eds), The Structure and Dynamics of New Zealand Industries. Palmerston North: Dunmore Press.

Easton, B. (1997). The health reforms, The Commercialisation of New Zealand. Auckland: Auckland University Press.

Fougere, G. (1994) The State and Health-Care Reform. In A. Sharp (ed.), Leap Into The Dark: The changing role of the state in New Zealand since 1984 (pp. 107-124). Auckland: Auckland University Press.

Fougere, G. (1997). Transforming Health Sectors: New Logics of Organising in the New Zealand Health Sector. Paper resented at the Postcards From the End of the Millennium: November 28-30, SAANZ, Massey University, Albany.

Government, NZ. (1997a) English to Nurses' Conference; Transcript. New Zealand Government.

Government, NZ. (1997b) Health Minister - Opportunities for Nurses. New Zealand Government.

Heydebrand, W. (1973) Hospital Bureaucracy: A comparative study of organizations. New York: Dunellen.

Imershein, A.W. \& Estes, C.L. (1996) From Health Serv- 
ices to Medical Markets: The commodity transformation of medical production and the non profit sector. International Journal of Health Services, 26(2), 221-238.

Lovell-Smith, J.B. (1966) The New Zealand Doctor and the Welfare State. Auckland: Blackwood \& Janet Paul.

N.Z. Ministry of Health, (1996) New Zealand health Workforce. Wellington: New Zealand Health Information Service.

N.Z. Ministry of Health, (1998) The 1997 Nursing Workforce Survey : Unpublished.

NZNO (1998) Building Partnerships: Developing the Future of Nursing. Wellington. NZ Nurses Organisation.

Papps, E. \& Olssen, M. (1997) Doctoring childbirth and regulating midwifery in New Zealand: a Foucauldian perspective. Palmerston North: Dunmore Press.

Parkes, C. (1991) The Impact of the Medicalisation of New Zealand's Maternity Services on Women's Experience of Childbirth. In L. Bryder (ed.), A Healthy Country: Essays on the Social History of Medicine in New Zealand. Wellington: Bridget Williams Books. (pp. 165 - 180)

Pye, M. (1998) Some Contradictions in the Current Debates on Nursing's Place in the Division of Health and Sickness Care Labour. New Zealand Journal of Industrial Relations, 23(3), 181 - 190.

Pye, M. \& Cullinane, J. (1997) Employment Relations in the New Zealand Health Sector: A Survey. In Morrison P.S. Labour, Employment and Work in New Zealand. Proceedings of the Seventh Conference 227-231.

Upton, S. (1991) Your Health \& Public Health: A Statement of Government Health Policy. Wellington: Minister of Health.

\footnotetext{
Author

Michael Pye is a $\mathrm{PhD}$ student at the

Department of Strategic Management and Leadership,

University of Waikato,

Private Bag 3015,

Hamilton.

E-mail: mjp@clear.net.nz
} 